\title{
Progress of Modern Pyrolysis Furnace Technology
}

\author{
Guotai Zhang, Bruce Evans \\ Technip USA Inc., Claremont, California, USA
}

Received 2012

\begin{abstract}
This paper presents the fundamentals of thermal pyrolysis and discusses the modern ethylene furnace technology and its design trends. Technip’s proprietary SPYRO ${ }^{\circledR}$ program is discussed for prediction of hydrocarbon cracking.

Keywords: Ethylene Furnace; Cracking Kinetics; Adiabatic Cracking; Non-Adiabatic Cracking; Radiant Coil; Convection Section; Burner and Selective Catalytic Reduction
\end{abstract}

\section{Introduction}

Ethylene, the simplest of olefins, is used as a base product for many syntheses in the petrochemical industry: plastics, solvents, cosmetics, pneumatics, paints, packing, etc. Today, the demand for ethylene is over 140 million tons per year with a growth rate of $3.5 \%$ per year.

The production of ethylene has been dominated by the steam cracking process since the end of World War II. The feed stocks for steam cracking are hydrocarbons such as shale gas, ethane, liquefied petroleum (LPG), naphtha, heavy gas condensate, and gas oil.

The cracking furnace is the heart of ethylene plant which consists of the radiant section, the convection section and transferline exchangers (TLE's) for waste heat recovery. (See Figure 1).

The objectives of this paper are to present the fundamentals of thermal pyrolysis, to introduce different cracking types in the furnace and to discuss the Technip modern furnace technology and design trends.

The various feedstock cracking kinetics have been simulated using Technip's proprietary SPYRO ${ }^{\circledR}$ program which is widely used by the industry for prediction of hydrocarbon cracking.

\section{Fundamentals of Thermal Pyrolysis}

Two scientific terminologies are used in the analysis below. [1] Bond Energy

Bond energy is a measure of bond strength in a chemical bond. The larger the bond energy, the stronger the bond and hence the higher temperature required to break it.

Bond Length

Distance between centers of bounded atoms is called bond length. There is a general trend in that the shorter the bond length, the higher the bond energy.

The general thermal cracking trend is listed below:

a) The $\mathrm{H}-\mathrm{H}$ bond energy is higher than the $\mathrm{C}-\mathrm{H}$ bond energy and $\mathrm{C}-\mathrm{H}$ bond energy is higher than the $\mathrm{C}-\mathrm{C}$ bond energy. Thus, the $\mathrm{C}-\mathrm{C}$ bond is easier to break than $\mathrm{H}-\mathrm{H}$ and $\mathrm{H}-\mathrm{C}$ bonds, and the $\mathrm{H}-\mathrm{C}$ bond is easier to break than the $\mathrm{H}-\mathrm{H}$ bond.

Table 1. Bond Length and Bond Energy.

\begin{tabular}{ccccccc}
\hline Bond Type & & H-H & H-C & C-C & C=C & C $\equiv \mathrm{C}$ \\
\hline Bond Length & Picometers* & 74 & 109 & 154 & 134 & 120 \\
Bond Energy & $\mathrm{kcal} / \mathrm{mol}$ & 104 & 99 & 83 & 147 & 200 \\
\hline
\end{tabular}

$* 1$ Picometer $=10^{-12} \mathrm{~m}$

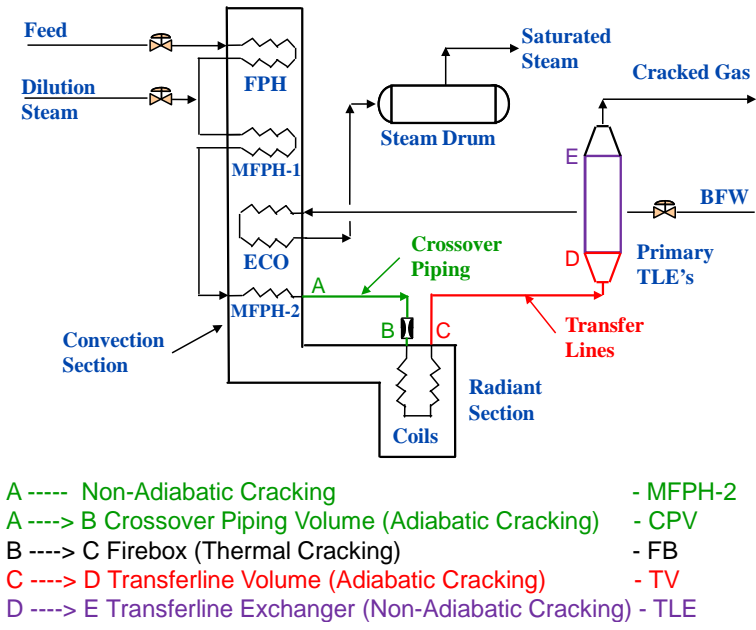

Figure 1. Ethylene cracking furnace. 
b) The dehydrogenation ability of a hydrocarbon depends upon its structure. Tertiary $\mathrm{H}$ is easily dehydrogenated and Primary $\mathrm{H}$ is more difficult to dehydrogenate. The dehydrogenation ability is in the order of

\section{Tertiary $\mathbf{H}>$ Secondary $\mathbf{H}>$ Primary $\mathbf{H}$}

c) Order of bond energy for Carbon-Carbon bonds is:

$$
\mathbf{C} \equiv \mathbf{C}>\mathbf{C}=\mathbf{C}>\mathbf{C}-\mathbf{C}
$$

d) Paraffin stability is lower with the molecular weight increase or the longer carbon chain length. There is a general trend in that the longer the carbon chain length the lower the bond energy and hence the easier cracking (breaking the C-C or $\mathrm{C}-\mathrm{H}$ bond) will occur. Therefore, the cracking temperature for hydrocarbon molecules with long carbon chain length will be lower.

e) Heat stability will be different for hydrocarbons with various structures. For hydrocarbons with the same numbers of carbon atoms, the heat stability order is

\section{Aromatics $>$ Naphthene $>$ Di-olefins $>$ Olefin $>$ Paraffin}

\section{Different Cracking Types in Pyrolysis Furnace}

Undesired cracking reactions can take place in the convection coil MFPH-2, crossover piping, transfer line or Transfer Line Exchanger (TLE) as shown in Figure 1. The cracking reactions which take place in the convection section and TLE are non-adiabatic cracking. The cracking reactions in the crossover piping and transfer line are adiabatic cracking reactions and those that occur in the radiant box are thermal cracking. [2]

The extent of both the non-adiabatic cracking reactions and the adiabatic cracking reactions depends on the hydrocarbon feed type, steam/carbon mole ratio, mixed feed temperature and pressure as well as mixed feed Residence Time (RT) in the crossover piping or furnace effluent RT in the transfer line volume.

\section{Modern Furnace Technology and Design Trends}

In this section we describe the state-of-art steam cracking technology and its design trends.

\subsection{Build Larger Ethylene Furnaces, Plants and Complexes}

Today, the largest single cell gas cracking furnace produces 210 KTA ethylene, and the largest single cell liquid cracking furnace produces $170 \mathrm{KTA}$ ethylene. Limits of these technologies have not yet been reached.

The largest ethylene plant has 1500 KTA ethylene capacity. New mega plants with 2000 KTA ethylene capacity are under consideration.

Currently, the world's largest ethylene complex is Formosa Petrochemical Corporation which produces about 3000 KTA ethylene.

\subsection{Develop Novel Radiant Coil}

New radiant coils have been developed to enhance heat transfer and increase furnace run length, selectivity or operating capacity. a) SFT (It has been granted a patent)

Technip has developed a new coil, Swirl Flow Tube (SFT) by bending tube process which can vary the amplitudes and pitches of the tube swirl to reduce tube skin temperature or increase run length and/or capacity.

For the same feed and feed rate with on-stream time of 50 days, the maximum Tube Metal Temperature (TMT) of SFT is about $50{ }^{\circ} \mathrm{C}$ lower than that of bare tube. In other words, feed rate can be increased $23 \%$ to reach maximum TMT of $1070{ }^{\circ} \mathrm{C}$ at 50 days.

Similar comparisons can be made on run length impact at constant capacity or on selectivity improvement with shorter coil length and short residence time.

\section{Swirl Flow Tube (SFT)}

- New coils geometry to improve selectivity and/or longer run length and/or higher capacity Recent Innovations:

- Swirl Flow Tubes (SFT) with varying amplitudes and pitches
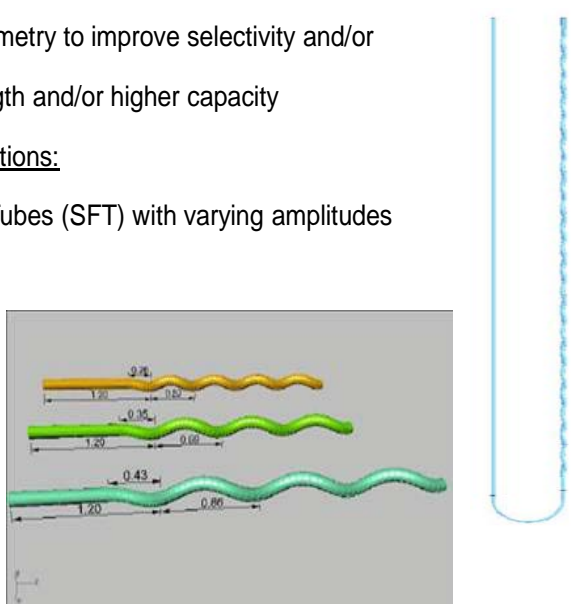

b) GK-7 Coil (It has been granted a patent)

A new coil called GK-7 has been developed by Technip, which has an improved layout of the Technip GK-6. It has following features [3]:

- Inlet tubes have an extra wide tube spacing

- Outlet tubes have an IN-LINE layout

- Small difference in TMT's between inlet/outlet passes

- Symmetrical tube layout

- Easier access for coil maintenance

A furnace with GK-7 coils is currently being constructed.

c) Cracking tube surface treatments

Cracking furnace tubes can use a surface treatment to reduce coking. For example, Kubota's ANK 400 achieves unprecedented furnace run length by dramatically lowering coke formation. The key to coke reduction is an inert, nanocrystalline spinel surface which has been proven to reduce both catalytic and pyrolytic coking.

d) Improved cracking tube alloys

Improved alloys can contain higher levels of chrome and nickel, but can also contain other additives. For example, the Schmidt + Clemens HT-E alloy, with a certain level of aluminium (Al) addition, is claimed to significantly reduce the effect of catalytic coking, while also offering protection against oxidation and carburization.

The positive impact on run length has been verified for HT-E compared to conventional 25/35 or 35/45 (Cr/Ni) alloys. 


\subsection{Use DP Transfer Line Exchanger (TLE)}

Direct coupled primary TLE (Double Pipe Type) is often used for mega ethylene cracking furnace to cool down the furnace effluent. DP primary TLE has following benefits:

- Mechanical cleaning is not required

- No tube sheet erosion or tube plugging

- Lower transfer line (adiabatic) volume

- Increase furnace availability

- Fewer fittings at the radiant coil outlets

\subsection{Optimize Burners and Furnace Firing Pattern}

Firebox program is used with the input of fuel gas/air data and heat release pattern to simulate the furnace firing behavior. The burner input information may update after the Vendor's burner test results. Finally, CFD is used to model the burner fluid dynamics in the firebox.

\subsection{Reduce Flue Gas NOx Emission}

There are two methods to reduce the amount of Oxides of Nitrogen (NOx) in the flue gas in order to meet US Environmental Protection Agency (EPA) requirements.

First is to use low NOx staged fuel or ultra low NOx staged fuel burners to reduce the NOx in the range of 0.045-0.06 lb/MMBtu (HHV, High Heating Value) in the flue gas.

Secondly, Selective Catalytic Reduction (SCR) system can be used to reduce the NOx down to $0.01 \mathrm{lb} / \mathrm{MMBtu}$ (HHV).

The SCR consists of SCR catalyst, an ammonia injection grid, and an ammonia vaporization skid. SCR technology is designed to react ammonia and NOx over a catalyst to produce nitrogen and water vapor. Catalyst is titanium vanadium on either a ceramic honeycomb type or corrugated type carrier. The catalyst is located in the convection section at a region where the temperature is suitable for catalyst operation.

\section{SPYRO ${ }^{\circledR}$ Yield Prediction Model}

The first SPYRO ${ }^{\circledR}$ program was released in 1977 , which has been continuously developed over 30 years.

SPYRO $^{\circledR}$ is a unique program for prediction of cracking furnace effluent yields as well as overall performance of the furnace. SPYRO ${ }^{\circledR}$ is the only program which is based on rigorous fundamental mathematical equations representing reaction kinetics of almost all chemical, thermo-chemical reactions in the pyrolysis furnace.

SPYRO $^{\circledR}$ is now used by more than $85 \%$ of the ethylene producing industry worldwide. The latest program version and kinetic model SPYRO ${ }^{\circledR}-7$ covers all hydrocarbon species from C2 to C42 and more than 7000 reactions. This version also allows better flexibility in establishing the furnace and heat recovery flowsheet.

\section{Conclusions}

1. There are different cracking modes at five various regions in the ethylene furnace. Major thermal cracking is in the radiant firebox.

2. Today, mega furnace sizes are 210 KTA ethylene and 170
KTA ethylene for single cell gas and liquid feedstocks, respectively.

\section{EFPS}

(ETHYLENE FURNACE PROGRAM SET)

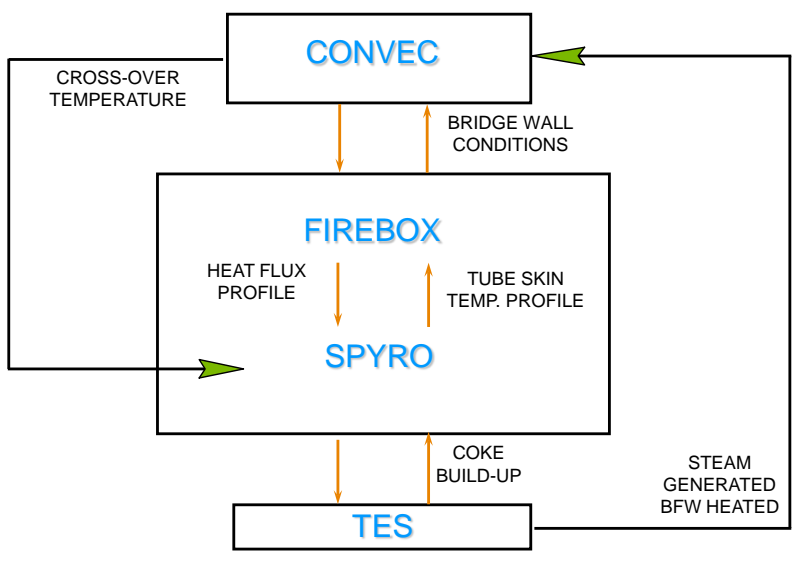
- SPYRO ${ }^{\circledR}$
Kinetic model for radiant coil Coking / runlength prediction Feedstock selection / cocracking evalution
- TES
Transferline Exchanger Simulation Coking / kinetics / runlength prediction - FIREBOX Combustion model coupled with SPYRO
- CONVEC Convection section simulation, complete process and steam/BFW system calculation
- EFPS
Complete furnace simulation with steam balance and feed / fuel flexibility analysis
- CFD

3. Novel radiant coils, enhanced tube layout and new types of tube metallurgy have been developed which enhance heat transfer and increase run length and/or capacity.

4. Double Pipe (DP) heat exchanger has been widely used as the primary TLE to quench the furnace effluent and generate high pressure steam.

5. Ultra low NOx staged fuel burners incorporating primary and secondary tips are used to reduce the NOx in the flue gas to 0.045 lb/MMBtu (HHV). Furthermore, Selective Catalytic Reduction (SCR) system can be used for the reduction of NOx to $0.01 \mathrm{lb} / \mathrm{MMBtu}$ (HHV).

\section{REFERENCES}

[1] "Optimization of Reformer Inlet Temperature based on Thermal Cracking of Feedstocks” at 2011 World Congress on Engineering and Technology (CET 2011)”, Guotai Zhang and Sanjeev Sekhri, Paper ID \#23177, Oct. 28 - Nov. 2, 2011, Shanghai, China.

[2] "Impact of Cracking at the Inlet and Outlet Transitions of Ethylene Furnace Radiant Sections”, Guotai Zhang and Bruce Evans, Presented at "Technip Ethylene Technology and SPYRO ${ }^{\circledR}$ International Conference", Jan. 30, 2008 in Abu Dhabi. "New Type 
of Cracking Furnace Radiant Coil”, Johan

[3] van der Eijk, Paper ID \#173546 at the AIChE 2010 Spring Na- tional Meeting, March, 21-25, 2010 in San Antonio, Texas, USA. 